\title{
EFEITO DO TURNO DE REGA E DA COMPETIÇÃO COM PLANTAS DANINHAS NO DESENVOLVIMENTO DE PLANTAS DE MILHO
}

\author{
Leonardo Leoni Belan' \\ Leonardo José Frinhani Noia da Rocha ${ }^{2}$ \\ Mateus Moreira Engelhardt ${ }^{3}$ \\ Lucas Santos Satiro ${ }^{4}$ \\ Wilker Pinheiro Lima ${ }^{5}$ \\ Leandro Pin Dalvi ${ }^{6}$
}

Resumo: A cultura do milho tem importância mundial por ter potencial produtivo e há aumento de produtividade em resposta à tecnologias de cultivo. No entanto, apesar altos índices de produtividade, vários fatores afetam o rendimento final da cultura, como por exemplo, as plantas daninhas. Assim, o objetivo nesse estudo foi analisar o efeito de diferentes turnos de rega e da competição com plantas daninhas no desenvolvimento de plantas de milho. O crescimento e o desenvolvimento das plantas de tiririca foram mais influenciados do que a cultura do milho, nos três turnos de rega analisados. Já a ocorrência simultânea do milho e da tiririca na mesma área, confirmou a competição entre as espécies, e consequentemente redução no desenvolvimento das plantas das duas espécies.

Palavras-chave: Tiririca; Cyperus rotundus; Interferência; Zea mays.

\footnotetext{
1 Mestrando - Produção Vegetal/Universidade Federal do Espírito Santo (UFES), Brasil. E-mail: belanagro@gmail.com.

2 Graduando - Agronomia/Universidade Federal do Espírito Santo (UFES), Brasil. E-mail: leofrinhanirocha@gmail.com.

${ }^{3}$ Mestrando - Ciência do solo/Universidade Federal de Lavras (UFLA), Brasil. E-mail: mateusme1@hotmail.com. ${ }^{4}$ Mestrando - Solos e nutrição de plantas/Escola Superior de Agricultura Luiz de Queiroz (ESALQ), Brasil. Email: santosatiros@hotmail.com.

5 Mestrando - Agroquímica/Universidade Federal do Espírito Santo (UFES), Brasil. E-mail: wilker_plima@hotmail.com.

6 Professor - Departamento de Agronomia/Universidade Federal do Espírito Santo (UFES), Brasil. E-mail: leandropin@yahoo.com.br.
} 